\title{
HUBUNGAN SIBLING RIVALRY DENGAN CEDERA PADA ANAK USIA BALITA DI DESA CIPACING KECAMATAN JATINANGOR
}

\author{
${ }^{1}$ Anggoro Susan Anggraeni, ${ }^{2}$ Ai Mardhiyah, ${ }^{3}$ Ikeu Nurhidayah \\ ${ }^{1,2,3}$ Fakultas Keperawatan Universitas Padjadjaran \\ E-mail:ikeu.nurhidayah@unpad.ac.id
}

\begin{abstract}
Abstrak
Latar belakang. Sibling rivalry terjadi pada anak usia balita yang memiliki saudara kandung, kecemburuan dan kebencian menyebabkan kompetisi untuk mendapatkan perhatian dari orangtua. Dampak sibling rivalry antara lain dapat menimbulkan risiko cedera fisik pada anak. Tujuan penelitian ini adalah untuk mengidentifikasi hubungan sibling rivalry dengan kejadian cedera pada anak usia balita di Desa Cipacing Kecamatan Jatinangor. Metode. Rancangan penelitian yang digunakan adalah deskriptif korelasi dengan pendekatan cross sectional. Sampel penelitian sebanyak 47 responden yang dipilih meggunakan teknik total sampling. Instrumen sibling rivalry dari penelitian Vevandi (2015). Instrumen cedera dikembangkan dari WHO. Data dianalisis menggunakan distribusi frekuensi dan ujia SpearmanRank. Hasil. Hasil penelitian menunjukkan 31 responden $(66 \%)$ memiliki anak yang mengalami sibling rivalry pada tingkat sedang dan 28 responden $(59,6 \%)$ anak mengalami cedera ringan. Terdapat hubungan yang lemah antara sibling rivalry dengan cedera pada anak usia balita di Desa Cipacing Kecamatan Jatinangor (p-value=0,048; r-value=0,290). Kesimpulan. Hasil penelitian menyarankan diperlukannya edukasi tentang pencegahan kecelakaan pada anak (bimbingan antisipasi pada orangtua).
\end{abstract}

Kata kunci: Balita, Cedera, Sibling rivalry

\begin{abstract}
Background. Sibling rivalry occurs in children under five aged who have siblings, jealousy and resentment leads to competition to get the attention of parents. This condition leads to a competition to get the attention of parents, which is often increasing the risk of physical injury in children. The purpose of this study was to identify the correlation between sibling rivalry and the incidence of injury in under fiver years old children at Cipacing Village, Jatinangor. Method.The method used in this study was descriptive correlation with cross sectional approach. Population of this study were parents who have at least two children below under five years old. The sample of this study was 47 respondents selected using total sampling technique. Sibling rivalry instrument from Vevandi's research (2015). Injury instruments developed from WHO. Data were analyzed using frequency distribution and Spearman-Rank test. Results. The results showed 31 respondents (66\%) had children who had sibling rivalry at moderate level and 28 respondents (59.6\%) children suffered minor injury. There is a weak relationship between sibling rivalry and injury in children aged under five in Cipacing Village, Jatinangor Sub-district ( $p$-value=0.048; r-value=0.290). Conclusion. The results suggest the need for education about prevention of accidents in children (anticipatory guidance for parents).
\end{abstract}

Key words: Injury, Sibling rivalry, Toddler

\section{PENDAHULUAN}

Keluarga merupakan lingkungan pendidikan yang utama bagi anak karena keluarga sebagai lingkungan pertama awal tumbuh kembang anak yang akan berpengaruh terhadap psikologis anak. Sebuah keluarga yang hanya memiliki seorang anak akan berbeda dengan keluarga yang akan atau sudah memiliki anak lebih dari satu. Dimulai dari cara memberikan pendidikan pada anak dan ketika sebuah keluarga akan kehadiran anggota/saudara baru, maka akan mengakibatkan anak usia balita mulai beradaptasi dengan perubahan yang baru terjadi (Potter \& Perry, 2013).

Peran orangtua sangat penting sebagai mediator antara anak yang satu dengan yang lain. Orangtua harus paham bagaimana cara memperlakukan anak-anaknya karena perbedaan usia kandung dapat memengaruhi 
cara seseorang beraksi antara saudara satu dengan saudara yang lain. perbedaan usia yang kecil cenderung akan meningkatkan perselisihan antarsaudara kandung (Hurlock, 2012).

Menurut Hockkenberry (2007), kejadian yang mengacu pada kecemburuan dan kebencian secara alamiah dari anak-anak untuk kehadiran anak baru dalam keluarganya atau ketika orangtua lebih memberikan perhatiannya kepada saudaranya disebut sibling rivalry. Selain itu sibling rivalry memiliki arti suatu perilaku antagonis atau permusuhan yang terjadi antara saudara kandung dan sering ditandai dengan perselisihan dalam merebutkan waktu, perhatian, cinta, dan kasih sayang yang diberikan oleh orangtua kepada masingmasing anaknya (Boyle, 1999 dalam Vevandi \&Tairas, 2015).

Beberapa tingkat kecemburuan dan persaingan setelah kelahiran saudara yang lebih muda adalah normal. Anak usia balita dikategorikan sibling rivalry ketika ada perasaan abnormal dalam intensitas dan durasi mereka (minimal satu bulan) disertai dengan beberapa derajat kerusakan sosial dan indikasi gangguan emosi (seperti regresi, amukan, dysphoria, gangguan tidur, perilaku oposisi, dan mencari perhatian yang berlebih terhadap satu atau kedua orangtua) (Carter \& Volkmar, 1992 dalam Vevandi \& Tairas, 2015).

Faktor yang memengaruhi sibling rivalry antara lain perbedaan usia yang dekat antara kakak dan adik, adanya pemutusan ASI secara mendadak, kesibukan orangtua sehingga persiapan yang diberikan dalam menghadapi datangnya adik sangat kurang, pola asuh yang over protective dan perilaku spesial dari orangtua, serta karakter anak (Putri, Deliana, \& Hendriyani, 2013). Dalam penelitian Rahmawati (2015) menjelaskan bahwa orangtua yang memiliki anak dengan jarak kelahiran dekat mengalami sibling rivalry. Selain itu, jenis kelamin juga memengaruhi terjadinya sibling rivalry. Jenis kelamin lakilaki dan perempuan memiliki reaksi yang sangat berbeda terhadap saudara kandungnya. Berdasarkan hasil penelitian Rahmawati (2012) bahwa kejadian sibling rivalry lebih besar dijumpai pada anak yang memiliki jenis kelamin yang sama (69.1\%) dibandingkan dengan anak yang tidak memiliki persamaan jenis kelamin $(30.9 \%)$.

Hasil penelitian Rofi'ah (2013), menyatakan bahwa orangtua yang menerapkan pola asuh permisif pada anak usia 1-5 tahun 46,9\% anaknya mengalami sibling rivalry. Pola asuh permisif yang diberikan oleh orangtua cenderung membanding-bandingkan anak yang satu dengan yang lainnya, tidak mempersiapkan anak untuk kelahiran adiknya, pilih kasih, serta cenderung tidak peduli terhadap anaknya. Oleh karena itu, anak akan menjadi lebih agresif, menjadi nakal, bertingkah seperti adiknya untuk mencari perhatian orangtuanya.

Dalam penelitian yang dilakukan oleh Putri, Deliana, dan Hendriyani (2013), bahwa dampak sibling rivalry ada tiga, yaitu dampak pada diri sendiri, pada saudara kandung dan pada orang lain. Adanya tingkah laku regresi, temper tantrum, emosi yang meledak-ledak, gangguan kepercayaan diri, dan perasaan dendam pada saudara merupakan dampak sibling rivalry pada diri sendiri. Akan tetapi, dampak sibling rivalry terhadap saudara kandung yaitu agresi, tidak mau membantu saudara, tidak mau berbagi dengan saudara, selalu mengadukan saudara kandungnya sendiri, dominasi pada saudara dan model negatif bagi saudara. Selain dampak sibling rivalry pada diri sendiri dan saudara kandung, juga berdampak pada orang lain yaitu perilaku buruk yang ditujukan pada orang- 
orang diluar rumah misalnya saudara sepupu, pembantu, guru, dan lain-lain.

Peristiwa sibling rivalry yang terjadi pada anak usia balita apabila tidak di atasi dapat menimbulkan pertengkaran yang akan mengakibatkan cedera pada saudara kandung yang lebih muda. Persaingan saudara pada masa kanak-kanak awal biasanya mengambil bentuk interaksi agresif seperti pertengkaran, memukul, dan mendorong sehingga dapat menyebabkan kecelakaan dan cedera. Berdasarkan penelitian yang dilakukan oleh Finkelhor, Turner, dan Ormrod dalam Dangkua, Monayo, Biomed, dan Pakaya (2015) menyatakan bahwa anak yang lebih muda mengalami dimensi cedera yang lebih serius dibandingkan dengan dimensi cedera pada anak yang lebih tua. Hal ini terjadi karena kekuatan fisik anak yang lebih tua lebih matang daripada anak yang lebih muda.

Menurut teori evolusi, kompetisi sibling diperkirakan meningkat karena tingkat kekerabatan genetis antara saudara kandung menurun (Salmon \& Hehman, 2014 dalam Tanskanen, Danielsbacka, \& Rotkirch, 2015). Pada penelitian sebelumnya menjelaskan bahwa kehadiran saudara secara signifikan dapat meningkatkan risiko kejadian cedera (Kendrick, Mulvaney, Burton, \& Watson, 2005; Tanskanen, Danielsbacka, \& Rotkirch, 2015).

Berdasarkan survei awal yang dilakukan peneliti di Desa Cipacing Kecamatan Jatinangor Kabupaten Sumedang dijumpai sepuluh keluarga yang memiliki kriteria dengan dua orang anak balita. Tujuh orangtua menyatakan bahwa setelah kelahiran anak kedua, anaknya selalu rewel, manja, sering cari perhatian dari orangtua, memukul dan mencubit serta mendorong adiknya ketika berebut mainan atau makanan. Satu orangtua mengatakan bahwa anaknya kembar dan jarang terjadi perdebatan, sesekali kakaknya pernah memukul dan merebut apa yang dipegang oleh adiknya.

Satu orangtua mengeluhkan stres saat kehamilan anak kedua karena anak pertamanya sangat rewel. Setelah kelahiran sang adik, kakak semakin manja dan rewel juga sering mencakar adiknya, berkelahi dan memukul sampai membuat luka adiknya. Satu orangtua mengatakan tidak ada masalah dari anak pertamanya saat kehamilan hingga kelahiran anak keduanya.

Berdasarkan latar belakang di atas peneliti tertarik untuk mengetahui bagaimana hubungan sibling rivalry dan cedera pada anak usia balita di Desa Cipacing Kecamatan Jatinangor.

\section{METODE PENELITIAN}

Rancangan penelitian yang digunakan pada penelitian ini adalah deskriptif korelatif dengan pendekatan cross sectional. Variabel yang diteliti, yaitu sibling rivalry dan cedera. Populasi dalam penelitian ini adalah orangtua yang memiliki minimal dua anak usia balita. Sampel penelitian berjumlah 47 responden yang dipilih menggunakan teknik total sampling. Kuesioner yang digunakan di antaranya sibling rivalry yang dikembangkan oleh Vevandi (2015) dan instrumen cedera dikembangkan oleh peneliti. Analisis data menggunakan distribusi frekuensi dan RankSpearman. 


\section{HASIL PENELITIAN}

Tabel 1.

Karakteristik Responden Orangtua dengan Anak Balita di Desa Cipacing Kecamatan Jatinangor Kabupaten Sumedang ( $=47)$

\begin{tabular}{lcc}
\hline \multicolumn{1}{c}{ Karakteristik } & Frekuensi $(\boldsymbol{f})$ & Persentase (\%) \\
\hline Pekerjaan & 41 & \\
Ibu Rumah Tangga & 4 & 87,2 \\
Swasta & 2 & 4,5 \\
PNS & 6 & \\
\hline Pendidikan Terakhir & 23 & 12,8 \\
SD & 16 & 48,9 \\
SMP & 2 & 34,0 \\
SMA & & 4,3 \\
Sarjana & 12 & \\
Usia & 23 & 25,5 \\
Remaja akhir (17-25 tahun) & 12 & 48,9 \\
Dewasa awal (26-35 tahun) & & 25,5 \\
Dewasa akhir (36-45 tahun) & 25 & \\
\hline Jumlah Anak & 12 & 53,2 \\
2 & 8 & 25,5 \\
3 & 2 & 17,0 \\
4 & & 4,3 \\
7 & 5 & \\
\hline Jarak Lahir Anak & 9 & 10,6 \\
0 & 15 & 19,1 \\
1 & 14 & 31,9 \\
3 & 4 & 29,8 \\
4 & & 8,5 \\
\hline Jenis Kelamin Anak 1 & 28 & 59,6 \\
Laki-laki & 19 & 40,4 \\
Perempuan & & \\
Jenis Kelamin Anak 2 & 28 & 59,4 \\
Laki-laki & & \\
Perempuan & & \\
\hline
\end{tabular}

Tabel 2.

Kejadian Sibling rivalry pada Anak Balita di Desa Cipacing Kecamatan Jatinangor Kabupaten Sumedang (N=47)

\begin{tabular}{ccc}
\hline Kategori & $(\boldsymbol{f})$ & $(\boldsymbol{\%})$ \\
Sibling rivalry & 9 & 19,1 \\
Tinggi & 31 & 66 \\
Sedang & 7 & 14,9 \\
Rendah & 7 \\
\hline
\end{tabular}

Dari tabel 2 di atas dapat diketahui bahwa sebagian besar anak $(66 \%)$ dari responden yang mengalami sibling rivalry ada pada tingkat sedang.
Tabel 3.

Kejadian cedera pada Anak Balita di Desa Cipacing Kecamatan Jatinangor Kabupaten Sumedang $(\mathbf{N}=47)$

\begin{tabular}{ccc}
$\begin{array}{c}\text { Kategori Sibling } \\
\text { rivalry }\end{array}$ & $(\boldsymbol{f})$ & $(\boldsymbol{\%})$ \\
\hline Cedera Ringan & 28 & 59,6 \\
Tidak cedera & 19 & 40,4 \\
\hline
\end{tabular}

Dari tabel 3 diketahui bahwa dari 47 responden, kejadian cedera pada anak dengan jarak kelahiran yang dekat $(59,6 \%)$ mengalami cedera dengan derajat ringan. 
Tabel 4.

Hubungan antara Sibling rivalry dengan Kejadian Cedera Pada Anak Balita di Desa Cipacing Kecamatan Jatinangor Kabupaten Sumedang $(\mathbf{N}=47)$

\begin{tabular}{ccccc}
\hline \multirow{2}{*}{$\begin{array}{c}\text { Sibling } \\
\text { rivalry }\end{array}$} & \multicolumn{2}{c}{ Cedera } & & \\
\cline { 2 - 3 } & Ringan & $\begin{array}{c}\text { Tidak } \\
\text { Mengalami }\end{array}$ & value & $\mathrm{R}$ \\
\hline Rendah & 8,5 & 6,38 & & \\
Sedang & 31,9 & 34,04 & 0,048 & 0,290 \\
Tinggi & 19,1 & 0 & & \\
\hline
\end{tabular}

Berdasarkan hasil uji spearman dapat diketahui bahwa nilai $\mathrm{p}<\alpha \quad(0,048<0,05)$, maka Ho ditolak dan $\mathrm{Ha}$ diterima. Terdapat hubungan yang signifikan antara sibling rivalry dengan cedera. Selanjutnya, berdasarkan nilai koefisien korelasi $(0,290)$ tingkat hubungan antara sibling rivalry dengan cedera pada penelitian ini ialah hubungan yang lemah.

\section{PEMBAHASAN}

1. Kejadian Sibling rivalry pada Anak Balita di Desa Cipacing Kecamatan Jatinangor Kabupaten Sumedang

Berdasarkan hasil analisa pada variabel sibling rivalry, lebih dari setengah responden besar responden memiliki anak yang mengalami sibling rivalry pada tingkat sedang. Tinggi rendahnya tingkat sibling rivalry yang dialami seseorang dipengaruhi oleh beberapa faktor di antaranya jarak kelahiran yang dekat, pemutusan ASI secara mendadak, pola asuh orangtua, karakter anak dan jenis kelamin anak (Putri, Deliana, \& Hendriyani, 2013).

Pada penelitian ini, anak usia balita di Desa Cipacing mengalami sibling rivalry dalam kategori sedang, disebabkan koping dari orangtua kepada anak yang lebih tua kurang. Koping yang diberikan orangtua kepada anak yang lebih tua berkurang ketika kehadiran adik baru yang membuat orangtua lebih berfokus pada anak yang lebih muda, sehingga anak yang lebih tua merasakan kekhawatiran akan kehilangan kasih sayang dari orangtua. Hal ini sesuai dengan studi kepustakaan dari Soetjiningsih dan Ranuh (2013) bahwa anak usia prasekolah biasanya "egosentris", yang berarti bahwa mereka hanya mempertimbangkan sesuatu dari sudut pandang mereka sendiri sehingga menyebabkan tingkat kecemburuan anak kepada saudaranya tinggi mengenai kasih sayang orangtua. Hal ini sesuai dengan pernyataan yang diisi oleh responden di dalam kuesioner sibling rivalry yang menyatakan kecemburuan, kebencian, dan rasa marah kepada saudara diisi oleh orangtua dengan hasil skor tinggi.

Berdasarkan item pernyataan yang menunjukkan bahwa nilai mean tertinggi berada pada item pernyataan nomor dua "Anak saya khawatir jika saya tidak membalas rasa sayangnya" dengan nilai mean $4,15$ ( $\mathrm{SD}=0,908)$. Hal ini menunjukkan bahwa anak yang mengalami sibling rivalry memiliki kekhawatiran yang berlebih mengenai perhatian dan kasih sayang dari orangtua. Kekhawatiran yang dirasakan anak sesuai dengan studi kepustakaan yang menyatakan bahwa sibling rivalry terjadi apabila anak merasa mulai kehilangan kasih sayang dari orangtua dan merasa bahwa saudara kandung adalah saingan dalam mendapatkan perhatian dan kasih sayang dari orangtua (Setiawati, 2008 dalam Laili \& Anika, 2014; Purnamasari, Bakara, \& Sutriyanti, 2014).

Fenomena sibling rivalry yang ditemukan peneliti selama pengambilan data sesuai dengan teori dan hasil penelitian tentang perilaku sibling rivalry. Berdasarkan hasil pengamatan peneliti, ditemukan beberapa perilaku sibling rivalry pada anak usia balita seperti memukul, mencubit, mencakar, menangis tanpa sebab, dan merebut mainan atau makanan adiknya. 
Anak yang mengalami sibling rivalry akan menunjukkan rasa benci, cemburu, cemas, dan marah yang akan menimbulkan permusuhan dengan saudara semakin bertambah (Boyle, 2012). Dengan hubungan saudara kandung yang mengarah pada kompetisi yang negatif tersebut dapat berdampak pada diri sendiri, saudara kandung, dan orang lain (Putri, Deliana, \& Hendriyani, 2013).

\section{Kejadian Cedera pada Anak Balita di Desa Cipacing Kecamatan Jatinangor Kabupaten Sumedang}

Berdasarkan hasil analisis pada variabel cedera didapatkan hasil bahwa dari 47 responden, lebih dari setengah responden mengalami cedera ringan dan kurang dari setengah responden tidak mengalami cedera. Faktor risiko terjadinya cedera disebabkan adanya kompetisi negatif antar saudara.Saudara dengan jenis kelamin yang sama, terutama laki-laki dengan saudara lakilaki, mungkin terlibat lebih intens dalam kompetisi yang dapat meningkatkan risiko cedera (Buist, Dekovic, \& Prinzie, 2013; Nitsch, Faurie, \& Lumma, 2012).

Berdasarkan hasil pengamatan selama pengambilan data bahwa kejadian cedera pada anak usia balita juga disebabkan karena faktor ekonomi dan pendidikan ibu yang rendah sehingga anak akan saling berebut makanan dan berujung pada kontak fisik atau bertengkar. Dari tabel 1 terlihat bahwa 48,9\% orangtua berpendidikan SMP. Hal ini sesuai dengan hasil penelitian yang menjelaskan bahwa sosial ekonomi yang rendah, daerah tempat tinggal, pendidikan ibu yang rendah, dan usia ibu yang rendah juga diasosiasikan dengan peningkatan risiko cedera kecil (Bruce, et.al., 2004; Hong, et.al, 2009; Kendrick, et.al., 2005; Pearce, et al., 2010).

Kompetisi pada anak balita dengan sibling rivalry dilakukan untuk merebut perhatian dan kasih sayang dari orangtua yang dapat menimbulkan risiko cedera fisik. Kejadian cedera fisik pada anak usia balita disebabkan karena orang lain ataupun diri sendiri. Hal ini dijelaskan oleh Brudvik (2000) bahwa 1,2\% kejadian cedera fisik oleh kesengajaan dari orang lain dan $0,2 \%$ disebabkan oleh diri sendiri. Kejadian cedera fisik yang sering terjadi pada anak usia balita di Desa Cipacing, yaitu cedera ringan seperti lebam, laserasi dan atau luka jatuh karena saling memukul, mencakar, dan mendorong. Cedera fisik ini juga dijelaskan oleh Bruce (2004) bahwa kebanyakan cedera yang terjadi pada anak, yaitu laserasi (41\%) dan jatuh (37\%).

Faktor lainnya yang memengaruhi kejadian cedera pada anak adalah lingkungan rumah seperti benda-benda yang ada di dalam rumah sehingga perlu adanya manajemen keamanan rumah untuk anak. Hal ini sesuai dengan penelitian Ahmed, Salman, dan Arafa (2014) yang memaparkan bahwa untuk mengatasi kejadian cedera ini orangtua perlu adanya pengetahuan bagaimana menyikapi mengenai manajemen keamanan rumah dan pertolongan pertama pada luka untuk mengurangi morbiditas dan mortalitas pada balita. Hal ini juga dijelaskan oleh Bruce, Lake, Eden, dan Denney (2004), dalam hal ini, orangtua harus mengamankan peralatan rumah tangga, obatobatan, dan benda-benda tajam dari jangkauan anak-anak untuk mencegah terjadinya cedera.

\section{Hubungan Sibling rivalry dengan Cedera pada Anak Usia Balita di Desa Cipacing kecamatan Jatinangor}

Hasil penelitian ini menunjukkan ada hubungan yang signifikan antara sibling rivalry dengan cedera pada anak usia balita di Desa Cipacing Kecamatan Jatinangor. Hubungan dengan arah positif antara sibling rivalry dengan kejadian cedera pada anak usia balita menunjukkan bahwa semakin tinggi 
kompetisi yang mengarah negatif antarsaudara maka semakin tinggi pula kejadian cedera. Selanjutnya berdasarkan nilai koefisien korelasi pada penelitian ini $(\mathrm{R}=0,290)$ dan melihat kriteria tingkat hubungan dari Gruilford (1956) menunjukkan bahwa tingkat hubungan antara sibling rivalry dengan cedera pada penelitian ini ialah hubungan yang lemah.

\section{SIMPULAN DAN SARAN}

Hasil penelitian menunjukkan bahwa kejadian sibling rivalry pada anak usia balita di Desa Cipacing Kecamatan Jatinangor menunjukkan bahwa lebih dari setengah responden memiliki anak yang mengalami sibling rivalry, yaitu $66 \%$ dalam kategori sedang. Sebagian besar anak usia balita dengan sibling rivalry mengalami cedera ringan.

Terdapat hubungan antara sibling rivalry dengan cedera pada anak usia balita di Desa Cipacing Kecamatan Jatinangor. Hubungan pada penelitian ini ialah hubungan rendah dengan arah positif. Semakin tinggi sibling rivalry maka semakin tinggi pula cedera fisik yang dialami anak usia balita.

\section{REFERENSI}

Ahmed, W. A., Salman, A. O., \& Arafa, K. A. (2014). Households' Preparedness For First-Aid Of Burns And Falls In Khartoum. African Journal of Medicine, 184-187. https://doi.org/10.1016/j.afjem.2014.0 $\underline{7.010}$

Arikunto, S. (2013). Prosedur Penelitian : Suatu Pendekatan Praktik. Jakarta: Rineka Cipta.

Bakwin. (2008). Behavior Disorder In Children. New York: W.B Saunder Company.

Best, J, W., \& Kahn, J. V. (1998).Research in Education. USA: Viacom Company.
Bruce, B. S., Lake, J. P., Eden, V. A., \& Denney, J. C. (2004). Children at Risk of Injury. Journal of Pediatric Nursing, vol 19, 121-127. https://doi.org/10.1016/S08825963(03)00144-1

Brudvik, C. (2000). Child Injuries In Bergen, Norway. Elsevier.

Brunner, \& Suddarth. (2002). Buku Ajar Keperawatan Medikal Bedah Volume 2. Jakarta: EGC.

Buist, K. L., Dekovic, M., \& Prinzie, P. (2013). Sibling Relationship Quality And Psychopathology Of Children And Adolescents: A Meta-Analysis. Elsevier. 97-106. https://doi.org/10.1016/j.cpr.2012.10.0 $\underline{07}$

Carter, A. S., \& Volkmar, F. R. (1992). Sibling rivalry Diagnostic Category or Focus of Treatment? In B. B. Lahey, \& A. E. Kazdin, Advance in Clinical Child Psychology volume 14 (pp. 289295). New York: Plenum Press.

Dangkua, N. S., Monayo, E. R., Biomed, M., \& Pakaya, A. W. (20015). Hubungan Persiapan Kelahiran Adik Baru Dengan Perilaku Sibling rivalry Pada Anak Di Wilayah Kerja Puskesmas Global Kecamatan Limboto Kabupaten Gorontalo. Jurusan Keperawatan FIKK UNG.

Depkes RI. (2013). Penuntun Hidup Sehat (Pencegahan Kecelakaan). Jakarta: Kemenkes RI.

El-Sabely, A. A., Yassin, A.-A. I., \& Zaher, S. A. (2014). Mother's Education And Her Knowledge About Home accident Prevention Among PreschoolChildren In Rural Area In Sharkia Governorate. IOSR Journal of Nursing and Health Science. 32-40.

Gallaher, J. R., Wildfire, B., Mabedi, C., \& Cairns, B. A. (2016). Intentional Injury Against Children In SubSaharan Africa: A Tertiary Trauma Centre Experience. Elsevier. 837-841. https://doi.org/10.1016/j.injury.2015.1 $\underline{0.072}$ 
Hanum, A. L., \& Hidayat, A. A. (2015). Faktor Domoinan pada Kejadian Sibling rivalry pada Anak Usia Prasekolah. THE SUN, 14-20.

Hockenberry, M. J., \& David Wilson. (2013). Wong's Nursing Care of Infants and Children. Edisi 8. Canada: Mosby Elsevier.

Hong, J., Lee, B., Ha, E. H., \& Park, H. (2009). Parental Socioeconomic Status And Unintentional Injury Deaths In Early Childhood: Consideration Of Injury Mechanism, Age At Death, And Gender. Elsevier, 313-319. https://doi.org/10.1016/j.aap.2009.08.0 $\underline{10}$

Hurlock, E. B. (2012). Psikologi Perkembangan. Jakarta: Erlangga.

Kendrick, D., Mulvaney, C., Burton, P., \& Watson, M. (2005). Relationships Between Child, Family and Neighborhood Characteristics and Childhood Injury: A Cohort Study. Social Science and Medicine. http://doi.org/10.1016/j.socscimed.200 5.04 .003

Kusbiantoro, D. (2014). Praktik Pencegahan Cedera Pada Anak Usia Toddler Ditinjau Dari Pengetahuan Dan Sikap Orangtua Tentang Bahaya Cedera Di Desa Kembangbahu Kecamatan Kembangbahu Kabupaten Lamongan. Surya, vol 02 no XVII.

Laili, S. I., \& Anika, S. L. (2014). Hubungan Peran Ibu Dengan Tingkat Kejadian Sibling rivalry Pada Anak Usia Toddler (1-3 Tahun) Di Desa Sumberrejo Purwosari Pasuruan. AKPER Bina Sehat PPNI MOjokerto.

Lilis Maghfuroh, L. (2012). Hubungan Sikap Orangtua Dengan Kejadian Sibling rivalry Pada Anak Usia 3-5 Tahun Di Desa Brengkok-Brondong-Lamongan. Jurnal Ilmiah

Ilmu-Ilmu Kesehatan,vol X, 9-13.

McHale, S. M., Updegraff, K. A., \& Whiteman, S. D. (2012). Sibling Relationships and Influences in Chilhood and Adolescence. Ntional Institutes of Health, 913-930.
Mubarak, W. I. (2007). Ilmu Keperawatan Komunitas Konsep dan Aplikasi. Jakarta: Salemba Medika.

Myhre, M. C., Thoresen, S., Grogaard, J. B., \& Dyb, G. (2012). Familial Factors And Child Characteristics As Predictors Of Injuries In Toddlers: A Prospective Cohort Study. BMJ Open, 1-8. https://doi.org/10.1136/bmjopen2011-000740.

Nitsch, A., Faurie, C., \& Lumma, V. (2012). Are Elder Sibling Helpers Or Competitors? Antagonistic Fitness Effects Of Sibling Interactions In Humans. Biological Sciences, 1-9. http://dx.doi.org/10.0.1098/rspb.2012. 2313.

Notoatmodjo, S. (2005). Metodologi Penelitian Kesehatan. Jakarta: Rineka Cipta.

Notoatmodjo, S. (2010). Promosi Kesehatan dan Ilmu Perilaku. Jakarta: Rineka Cipta.

Nursalam. (2013). Konsep dan Penerapan Metodologi Penelitian Ilmu Keperawatan. Jakarta: Salemba Medika.

Pearce, A., Li, L., Abbas, J., Ferguson, B., Graham, H., Law , C., et al. (2010). Does Childcare Influence Socioeconomic Inequalities In Unintentional Injury? Findings From The UK Millennium Cohort Study. Jurnal of Epidemiology \& Community Health, 161-166. https://doi.org/10.1136/jech.2009.0926 $\underline{43}$

Potter, P. A., \& Perry, A. G. (2005). Fundamental Nursing: Consepts, process, and practice sixth edition. St. Louis: Mosby Year Book.

Potter, P. A., \& Perry, A. G. (2010). Fundamental of Nursing. Jakarta: EGC.

Purnamasari, D., Bakara, D., \& Sutriyanti, Y. (2014). Hubungan Tingkat Pengetahuan Ibu dengan Kejadian Cedera. Jurnal Kesehatan, 182-188.

Putri, A., Deliana, S., \& Hendriyani, R. (2013). Dampak Sibling rivalry Pada 
Anak Usia Dini. Journal Unnes, 3337, http://journal.unnes.ac.id/sju/index.ph $\mathrm{p} / \mathrm{dcp}$

Rahmawati, I. (2015). Hubungan Jarak Kelahiran Dengan Kejadian Sibling rivalry Di Desa Pelemkerep Kecamatan Mayong Kabupaten Jepara. Jurnal Kesehatan dan Budaya, vol 08 no 1.

Reading, R., Jones, A., Haynes, R., Daras, K., \& Emond, A. (2008). Individual Factors Explain Neighbourhood Variations In Accidents To Children Under 5 Years Of Age. Social Science and Medicine, 915-927. https://doi.org/10.1016/j.socscimed.20 08.05 .018

Rofi'ah, S. (2013). Pola Asuh Orangtua Dengan Kejadian Sibling rivalry Pada Anak Usia 1-5 Tahun. Poltekes Kemenkes Semarang Prodi D III Kebidanan Magelang, vol 1 no 3.

Santrock. (2002). Life- Span Development. Jakarta: Erlangga.

Smith, D., Kirkwood, G., Pott, J., Kourita, L., Jessop, V., \& Pollock, A. M. (2015). Childhood Injury in Tower Hamlets: Audit of Children Presenting with Injury to An Inner City A\&E Department in London. Elsevier, 1131-1136.

Soetjiningsih, \& Gde Ranuh, I. N. (2013). Tumbuh Kembang Anak Edisi 2. Jakarta: EGC.

Sugiyono. (2010). Metode Penelitian Kuantitatif Kualitatif dan $R \& D$. Bandung: Alfabeta.
Sulistiyawati, A. (2009). Buku Ajar Asuhan Kebidanan Pada Ibu Nifas, Edisi Pertama, Andi. Yogyakarta.

Tanskanen, A. O., Danielsbacka, M., \& Rotkirch, A. (2015). More Unintended Injuries in Half Sibling Than Full Sibling Household in the UK. Department of Social Research, University of Helsinki, Finland, 177182. $\quad$ http://doi.org/10.1027/16140001/a000171

Vevandi, T., \& Tairas, M. M. (2015). Hubungan Sibling rivalry Dengan Motivasi Berprestasi Pada Remaja. Jurnal Unair, vol 4 no 1, 46-56.

Wang, H., Liu, Y.-X., Lin, Y., \& Shen, M. (2011). Incidence And Risk Factors Of Non-Fatal Injuries In Chinese Children Aged 0-6 Years: A CaseControl Study. Elsevier, 521-524. https://doi.org/10.1016/j.injury.2010.0 2.010

Winslow. (2006). A Social Skills Approach for Children and Adolescent. USA: Speechmark Publishing.

Wong, D. L., Hockenberry, M., Wilson, D., Winkelstein, M. L., \& Schwartz, P. (2008). Buku Ajar Keperawatan Pediatrik. Jakarta: EGC.

Zanden, J. W. (2003). Human Development Fifth Edition. USA: Mac Grow Hiil.

Zulkifli, L. (2001). Psikologi Perkembangan. Bandung: PT. Remaja Rosdakarya. 